\title{
BACTERIAL WILT OF TOBACCO IN PUERTO RICO AND ITS INTERTRANSIMISSION TO OTHER SOLANACEOUS HOSTS
}

\author{
By Arturo Roque \\ Assistant Phytopathologist, Insular Experiment Station, Río Piedras, P. R.
}

Although bacterial wilt of the Solanaceae has been repeatedly reported by various investigators from Puerto Rico, Henricksen (2), Stevenson (9), Stevenson and Rose (8), Smith (7), Thomas (11), López (4), Seaver and Chardon (6), Cook (1), and more recently by Nolla (5), attacking tomato, eggplant, pepper, potato and other plants*, the disease has never been found naturally in tobaceo nor has been produced artificially by inoculation with supposedly pure cultures of B. solanacearum E. F. S. from other hosts. Cook (1.e.) suspected the pathogene to be a different one when his cross inoculations with the organism from eggplant succeeded on tomatoes and peppers but failed on tobacco. Nolla (l.c.) in a very comprehensive study of the disease concluded that the Puerto Rico organism, although morphologically similar to B. solanacearum E. F. S. was a strain incapable of infecting tobaceo. He suggested, however, the possibility of all varieties of tobaceo on the island being resistant to the organism.

The present investigation was initiated with the purpose of ascertaining why tobaceo was not attacked by the Puerto Rican strain and, if so, the relationship between the tobacco organism and the one attacking other Solanaceous hosts of economic importance, viz., tomato, eggplant, pepper and potato. With the introduction of new tobacco varieties as a means of improving our standard types and, more recently, with the expansion of the vegetable growing industry into what was formerly tobaceo land, the importance of elucidating this point not only has a purely scientific value but also a decided economic importance.

\section{HISTORY}

The writer found what was apparently the first observed case of bacterial wilt on tobaceo in Puerto Rico in the summer of 1931, among two of our standard varieties, Ceniza and Utuado, growing in a field that for the last 10 years has been planted with sugar eane and, more recently, with strawberries. The plants were about 18

\footnotetext{
* Zinias (Crassina elegans (Jacq.) Kuntze); Solanum torvum L.; Solanum caribaeum Dunal. Undoubtedly many other plants are attacked under our conditions.
} 
inches high and growing rapidly. Two of the Utuado plants were carefully pulled and their root systems washed. No symptoms of fungus attack was evident and the roots, except for the end of the main branch, appeared to be healthy. After stripping the plants of their leaves, the greater part of the stem was cut off until almost a solid core of woody tissue near the base of the stalk was left. The roots were then set in a beaker with distilled water in such a way as to leave the stub above the surface. In a few minutes, a slimy, brownish exudation appeared on the cut surfaces. A microscopic examination of the exudate, revealed the presence of enormous numbers of motile, rod shape organisms, similar in morphology to $B$. solanacearum E. F. S.

Agar plates from sterile water suspensions of the ooze failed to develop colonies after five days, but streaks made directly from the exudate made good growth. From these slants, agar plates were poured which in 48 hours developed watery, translucent colonies. Sub-cultures were then made from these colonies and in eight days developed the typical brown pigment characteristic of this organism.

\section{Morphologic Symptoms.}

In the Field.-The symptoms of the disease when occurring naturally in the field are typical and distinct. The first indication is the sudden wilting of one or more of the youngest leaves. When only one leaf wilts it is usually the third or fourth youngest from the top. The leaves wilt either totally or partially; when partially, the tip or only the area of the blade at either side of the midrib withers; when the whole leaf wilts, it droops, so that only the ventral side of the leaf is visible. The wilting and drooping of a single leaf near the top is an unmistakable early symptom of the disease. These early manifestations of infection are usually evident late in the morning hours when a bright day follows previous heavy rains.

If the variety is resistant to the malady, the symptoms progress no further and in a week or two the plant completely recovers. Because of the fact that all of our standard varieties are highly resistant to infection, as will be demostrated further on, this may explain the reason why the disease has been previously overlooked.

In case of susceptible varieties, successive wilting of the other leaves follows, usually the older ones, and the normal growth of the plant is checked so that adjacent healthy plants shortly outgrow them. Wilting is not uniform along the plant, but usually one side is more wilted than the other or not wilted at all. Wilted areas may show a slight yellowish discoloration, but a marked chlorosis is not 
typical. The leaves finally rot, in some cases, only the stalk with a few stripped midribs remaining. If hot dry weather follows the initial symptoms, the leaves are irregularly scalded, in a short time dry up, become brittle and desintegrate. With moist weather, the leaves gradually turn yellow, then brown and finally rot without becoming brittle. In advanced stages, the stem blackens, becomes hollow and shrivels up.

When the roots of diseased plants are examined dark grayish to black, slightly sunken blotches are often present in the main branches. Usually the rootlets arising from these branches are dead and their cortex is easily removed. When cross sections of the affected roots are made, droplets of a slimy ooze appear on the cut surfaces. For diagnostic purposes this is the critical evidence of infection by bacterial wilt.

Under Puerto Rican conditions, the writer had no difficulty in differentiating between fungus wilt as produced by Rhizoctonia solani Kühn, Phytophthora parasitica var. nicotianae Tucker, and bacterial wilt, as soon as the early symptoms of both types of infection are evident. In the former cases, the wilting is sudden and general, that is, practically all the leaves wither and droop simultaneously and a marked chlorosis is immediately noticeable. Wilted plants do not recover from day to day with the advent of moist weather and cloudy mornings as plants attacked by bacterial wilt do in the eariy stages. So clear cut is the difference that the writer never failed to obtain critical signs of bacterial wilt on plants marked as such as soon as the first symptoms were observed.

Symptoms were observed at all stages of growth from three weeks after setting plants in field.

On Inoculated Plants.-The symptoms manifested by inoculated plants in pots were identical in every respect to those observed under field conditions, especially so, in the early stages. Inoculated plants, however, seldom were completely destroyed; partial or complete recovery being oftener the case. In many instances, recovered plants would exudate the slimy ooze even when cut 10 inches above the point of inoculation.

Brown and sunken longitudinal streaks along the stem were often produced by inoculated plants, but this symptom was never observed in the field. When these areas are punctured, exudation of ooze follows.

Dwarfing and undeveloped root systems are also pronounced symptoms of inoculated plants. 


\section{Histologic Symptoms}

Bacterial wilt is primarily a disease of the vascular tissues of the plant. In tobaceo as well as in other suscepts studied, however, the pith is nearly always affected and in many cases also the cortex.

Tranverse sections of affected parts of the roots or stems shows the vessels completely occluded with the bacterium. There is a pronounced discoloration of the wood which varies in color from reddish brown to dark brown. Shortly after the cut surfaces are cxposed a sticky exudate oozes out of the vessels in tiny droplets whic's rapidly enlarge and coalesce. Both the consistency and the color of this ooze varies with individual cases, in some instances being watery while in other it is very thick. The color varies from pearl white in plants recently infected to a very dark brown in advanced cases, although individual droplets from the same stem may differ among themselves as to color.

The pith is nearly always affected and when the attack is severe it is rapidly disorganized. As a result the stem collapses, forming indentations and twisting around. It is also stained brown, but to a lesser degree than the woody tissues. In some cases the bacterium invades the cortex forming necrotic areas which enlarge with the advance of the infection. The woody tissues, although becoming functionless, are not disorganized until invaded by secondary saprophytes.

\section{Етіоцоят.}

Morphological, cultural and pathogenecity studies establishes the organism responsible for bacterial wilt of tobacco in Puerto Rico as identical to Bacterium solanacearum E. F. S. (Phytomonas solanacearum (E. F. S.) Com. S. A. B.)

The pathogene is extensively disseminated throughout the island and is responsible for a similar disease in other Solanaceous hosts among which tomato, eggplant, pepper, and potato are the most important.

Morphological and Cultural Characteristics.

The following characteristies are typical for the organism under discussion :

Rods, $0.5 \mu$ in width, varying in length from $1.0 \mu$ to $1.5 \mu$; motile by a single polar flagelum (two preparations stained by Cesares-Gil method) which is 3 or 4 times longer than the cell; motility is best observed in hanging drops of fresh ooze or in broth cultures 48 hour's old at room temperature $\left(25^{\circ} \mathrm{C}\right.$. to $30^{\circ} \mathrm{C}$. $)$. The cells stain well 


\section{Histologic Symptoms}

Bacterial wilt is primarily a disease of the vascular tissues of the plant. In tobacco as well as in other suscepts studied, however, the pith is nearly always affected and in many cases also the cortex.

Tranverse sections of affected parts of the roots or stems shows the vessels completely occluded with the bacterium. There is a pronounced discoloration of the wood which varies in color from reddish brown to dark brown. Shortly after the cut surfaces are exposed a sticky exudate oozes out of the vessels in tiny droplets whic's rapidly enlarge and coalesce. Both the consistency and the color of this ooze varies with individual cases, in some instances being watery while in other it is very thick. The color varies from pearl white in plants recently infected to a very dark brown in advanced cases, although individual droplets from the same stem may differ among themselves as to color.

The pith is nearly always affected and when the attack is severe it is rapidly disorganized. As a result the stem collapses, forming indentations and twisting around. It is also stained brown, but to a lesser degree than the woody tissues. In some cases the bacterium. invades the cortex forming necrotic areas which enlarge with the advance of the infection. The woody tissues, although becoming functionless, are not disorganized until invaded by secondary saprophytes.

\section{ETTOLOG:}

Morphological, cultural and pathogenecity studies establishes the organism responsible for bacterial wilt of tobacco in Puerto Rico as identical to Bacterium solanacearum E. F. S. (Phytomonas solanacearum (E. F. S.) Com. S. A. B.)

The pathogene is extensively disseminated throughout the island and is responsible for a similar disease in other Solanaceous hosts among which tomato, eggplant, pepper, and potato are the most important.

\section{Morphological and Cultural Characteristics.}

The following characteristies are typical for the organism under discussion:

Rods, $0.5 \mu$ in width, varying in length from $1.0 \mu$ to $1.5 \mu$; motile by a single polar flagelum (two preparations stained by Cesares-Gil method) which is 3 or 4 times longer than the cell; motility is best observed in hanging drops of fresh ooze or in broth cultures 48 hours old at room temperature $\left(25^{\circ} \mathrm{C}\right.$. to $30^{\circ} \mathrm{C}$. $)$. The cells stain well 
with ordinary anilin dyes but specially so with carbol fuchsin. In good preparations a more pronounced staining of the polar regions as well as a plain constriction at the center are evident.

Standard nutrient agar plates begin to show surface colonies in from one to two days; in general these are small, circular and slightly raised, transparent at first, resembling tiny drops of water on the surface of the agar, changing to whitish 'when seen by reflected light in one to two days, but brownish by transmitted light and producing a brown pigmentation which varies in intensity from very light to dark brown after a week old, and diffuses into the agar. Sub-surface colonies are variously shaped, usually elliptical.

Nutrient agar and litmus lactose agar slants show a filiform type of growth; the agar in the latter case acquiring a more intense blue color with age particularly near the region of growth. The streaks are semi-liquid during the first few days and run into the condensation water if kept upright.

Gelatin stabs show no liquifaction when two weeks old.

Milk is cleared without precipitation of the casein and the medium acquires a bright brownish hue. Litmus milk becomes more intense blue with age without precipitating.

Broth cultures become clouded in 24 hours when a recently isolated culture is used; old cultures require a longer time for clouding the medium. In a few days a white precipitate is deposited at the bottom of the tube and the liquid becomes intensely clouded, with or without the formation of a very slight pelicle. As the cultures become old, the supernatant liquid becomes clear and develops a color which varies from amber to dark brown.

Growth on potato slants is at first watery, spreading, whitish or yellowish in color, later turning brown and the water becoming heavily clouded.

On Dunham's solution growth is similar to that of broth eultures. No growth has been observed on Cohn's solution.

No gas or acid is produced from saccharose, dextrose, glucose, maltose, lactose or mannit broths.

Nitrates are not reduced; indole is not produced.

Spores have not been observed. The organism is aerobic and gram negative.

The length of time for which the organism remains viable in pure cultures is variable; good growth has been obtained from broth cultures three months old. Liquid cultures remain viable for a longer period than cultures on solid media. 
The above description of cultural and morphological characters corresponds to the ones given by Smith (l.c.), Stanford and Wolf (10), Nolla (l.c.) and other investigators elsewhere for B. solancicearum E. F. S.

\section{INOCULATIONS.}

Methods and Inoculum.-The irregular behavior of plants inoculated with B. solanacearum E. F. S., was first noted by Smith (1.c.) and confirmed by practically all investigators on the subject since then. Similar difficulties were encountered by the writer. These were augmented by the fact that the organism rapidly or immediately loses its pathogenic ability when artificially cultured.

In an effort to obviate these difficulties, several methods were tried in the early stages of these studies, two of which were finally idopted in conducting inoculations and cross-inoculations with marked success.

Both the aerial and the underground parts of the suscepts were inoculated. Except in two or three instances, all inoculations performed above ground failed. They even failed when conditions for the development of the organism at the point of inoculation were provided. Identical inoculum, when used simultaneously underground, on plants grown alike, would reproduce the symptoms of the disease.

Sub-cultures from poured plates; broth cultures made directly from ooze or from sub-cultures; streaks made directly from ooze; colonies from poured plates; sub-cultures on potato slants; ooze directly from diseased plants, and pieces of diseased wood were used as sources of inoculum. Except when ooze or pieces of wood were used, the age of each of the various cultures employed varied in from 1 to 7 days. Pieces of wood were invariably used the same day and ooze was used when not more than 48 hours old.

Of these, agar streaks made directly from ooze, pieces of wood and pure ooze were the most successful sources of inoculum; the last two mentioned giving very consistent results. Nolla (l.c.), pointed out that inoculations with ooze scarcely ever failed.

Symptoms produced by sub-ulture inoculations no matter on which medium grown were usually of a localized nature; there is a slight brownish discoloration following the vascular bundles for a short distance below and above the point of inoculation or the pith was sometimes affected. Critical symptoms, however, were rarely, if ever, obtained. 
In performing most of the inoculations upon which the conclusions arrived at in this paper are based, the usual procedure was to inoculate young, rapidly growing plants in 8-inch pots in sterilized soil, about one inch below the surface of the ground, either with ooze or with pieces of diseased wood from the same or other suscepts studied. The necessary ooze was obtained from roots and stems if recently wilted plants in the field. The soil around the stem near the surface of the ground was carefully removed and the stem washed with distilled water at the desired place. A slight injury with the end of a sharp scapel so as to pierce the woody cylinder was made and the ooze inserted at that point. The soil was then replaced and the plants watered once or twice a day until discarded. Checks were similarly treated, except that no inoculum was provided.

When pieces of diseased wood were used, thin slices of the material were cut with a sterile razor in such a way that one side of the section was thicker than the other, and kept in sterile water until used. With a sharp scapel, a longitudinal cut was made after proceeding as above. The end of the scapel was not removed until, with a pair of tweezers, the slip of wood, thinner edge first, was inserted into the cut. The whole scheme is in the nature of an underground graft.

These two methods were equally successful, but because of the large amount of ooze required when making extensive inoculations, the latter was much more convenient.

Pathogenicity.-Tobaceo plants inoculated as above from nat. urally wilted plants developed typical wilt symptoms in from 4 to 10 days. When resistant varieties were used recovery slowly followed these early symptoms; when susceptible varieties were inoculated, the symptoms usually terminated in the death of the plants.

Broth cultures of the inoculum were plated when two days old and sub-cultures made. Soon after the symptoms on inoculated plants were well defined, the plants were pulled, washed and examined for the critical sign of infection: exudation of ooze for some distance above or below the point of inoculation. Sub-cultures of this ooze made as above were then compared with the original ones. In every case, they were found to be morphologically and physiologicaliy identical.

Agar plates from broth cultures of the ooze nearly always yielded a single type of colony with slight or no contaminations. This is particularly the case when fresh ooze from recently wilted plants is collected as far up in the stem as possible. Parallel inoculations with these typical colonies with few exceptions failed, while those made 
with ooze were successful. This points to the rapidity with which the organism losses its infective powers. Sometimes abundant fungus contaminations (Fusarium sp. and Actinomyces sp.) would appear in the plates. In these cases, the results obtained from ooze or wood inoculations were not considered.

In all inoculation work done, an average of two checks for every 10 plants treated were carried. They always failed to show the disease.

\section{INTERT,RANSMISSION.}

Nolla (1.c.) has shown that B. solanacearum E. F. S., as occurs in Puerto Rico, is intertransmissible to tomato, eggplant, pepper and potato. In an effort to establish the pathogenic relationship between the tobaceo organism and these hosts, over 500 inoculations were made, more than one-half of which were successful. The routine procedure was to determine first the pathogenicity of the ooze from each suscept on itself and then to make direct and reciprocal inoculations between each of the five species under study.

Sufficient positive reactions were obtained in each case to warrant the conclusion that the organism responsible for bacterial wilt of tobaceo in Puerto Rico is equally pathogenic to the other hosts under consideration and they, in turn, are equally pathogenic not only among themselves but also to tobaceo.

\section{VARIETAL SUSCEPTIBILITY.}

Through the courtesy of Dr. R. F. Poole, of the North Carolina State College of Agriculture, the writer received seed of three flue cured varieties of tobaceo: Cash, White Stem Oronoco and Adeock, known to be susceptible to bacterial (Granville) wilt. When tested, the Adcock seed failed to germinate.

In the Summer of 1931, 200 plants of each of the Cash and Oronoco varieties were grown in a field known to be heavily infested with the organism, as demonstrated by the high incidence of infection when either tomatoes or susceptible eggplants were grown on it. They were planted alternately in 10 rows, $3 \mathrm{ft}$. apart, 40 plants to a row. Hot, rainy weather followed for weeks after transplanting to the field. A perfect stand was secured by continued replantings. Notes on incidence of wilt were taken once a week, as soon as the first symptoms* were observed. The results are given in table 1.

* Before finally recording any plants showing symptoms as positive, a critical examins. tion for bacterial exudate was made. 
TABLE I

INCIDENCE OF WILT ON TWO IMPORTED TOBACCO VARIETIES

\begin{tabular}{|c|c|c|c|c|}
\hline Variety & Population & Healthy & Wilted & \& Wilted \\
\hline $\begin{array}{l}\text { Cash } \\
\text { White Stem Oronoco } \ldots \ldots \ldots \ldots \ldots \ldots \ldots \\
\end{array}$ & $\begin{array}{l}200 \\
200\end{array}$ & $\begin{array}{l}87 \\
53\end{array}$ & $\begin{array}{l}113 \\
147\end{array}$ & $\begin{array}{l}56.5 \\
73.5\end{array}$ \\
\hline
\end{tabular}

The results demonstrated that these varieties are highly suscer)tible to the disease under favorable conditions for infection.

A more extensive trial was conducted in the same field early in the Spring of 1932. Besides the above mentioned types, our three most popular varieties: Virginia, Ceniza and Utuado, and a vigorous variety brought from Colombia in 1929 by Dr. J. A. B. Nolla, were included in the test. The same plan of planting as explained in the previous trial was followed. The weather was eool and dry at the time of planting and remained so for two or three weeks after. In consequence, the plants failed to grow rapidly and the symptoms of bacterial wilt appeared very late, even at flowering time with the early varieties. Symptoms of fungus wilt, however, showed much earlier and to such an unexpected extent that it became obvious that this factor had to be taken into consideration in analyzing the results. These are given in table 2 .

TABLE II

INCIDENCE OF FUNGUS AND BACTERIAL WILT ON LOCAL AND IMPORTED TOBACCO VARIETIES

\begin{tabular}{|c|c|c|c|c|c|c|}
\hline Variety & + & $\begin{array}{l}\text { Plants } \\
\text { infected } \\
\text { with } \\
\text { fungus } \\
\text { wilt }^{*}\end{array}$ & $\begin{array}{l}\text { Percent } \\
\text { infected } \\
\text { with } \\
\text { fungus } \\
\text { wilt }\end{array}$ & $\begin{array}{l}\text { Plants } \\
\text { infected } \\
\text { with } \\
\text { bacterial } \\
\text { wilt }\end{array}$ & $\begin{array}{c}\text { Percent } \\
\text { infected } \\
\text { with } \\
\text { bacterial } \\
\text { wilt from } \\
\text { total No. } \\
\text { of plants }\end{array}$ & $\begin{array}{c}\text { Percent } \\
\text { infected } \\
\text { with } \\
\text { bacterial } \\
\text { wilt from } \\
\text { healthy } \\
\text { plants only } \\
* *\end{array}$ \\
\hline 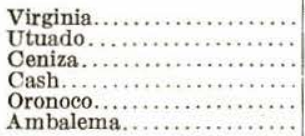 & $\begin{array}{l}180 \\
201 \\
202 \\
201 \\
204 \\
212\end{array}$ & $\begin{array}{l}39 \\
22 \\
65 \\
98 \\
63 \\
33\end{array}$ & $\begin{array}{l}21.66 \\
10.95 \\
32.12 \\
48.75 \\
30.88 \\
15.56\end{array}$ & $\begin{array}{l}15 \\
18 \\
13 \\
23 \\
46 \\
30\end{array}$ & $\begin{array}{r}8.33 \\
8.99 \\
6.43 \\
11.44 \\
22.54 \\
14.15\end{array}$ & $\begin{array}{r}10.63 \\
10.05 \\
9.48 \\
22.33 \\
32.62 \\
16.75\end{array}$ \\
\hline
\end{tabular}

* Rhizoctonia solani Khün and Phytopht:ora parasitica var. nicotianae Tucker.

** The per cent of bacterial wilt from healthy plants only, i.e., from those remaining after deducting the ones infected with fungus wilt.

The writer is inclined to consider the percentage obtained in the last column as a more accurate estimate of the true incidence of infection for each variety under the conditions of the experiment because the early invasion of plants attacked with fungus pathogenes prevented the infection with $B$. solanacearum, which, as stated, developed much later in this particular trial. Furthermore, not a single plant attacked with fungus wilt was found to be also infected 
with bacterial wilt, when such a condition ought to have been possible had every plant had an equal chance of infection with the bacterial pathogene.

The results show that tobaceo varieties exhibit a wide range of susceptibility to the disease and that, even under conditions of high soil infestation, our standard varieties are highly resistant to the disease. The Ambalema is less so and the North Carolina varieties very susceptible. Furthermore, our standard varieties, although exhibiting unmistakable signs and symptoms of the malady, were able in practically every case, to recover rapidly without any appreciable loss and the same is true, although to a lesser extend, of the Ambalema. Both the Cash and White Stem Oronoco varieties presented not only more severe symptoms of a progressive nature, but in the majority of cases every diseased plant was an actual loss.

With repect to the two last-mentioned varieties, the results are in harmony with those presented in table 1 . The fact is also brought out that the disease is much more severe during hot, rainy weather than during the cool, semi-dry season. Because tobacco is grown in Puerto Rico under the last mentioned conditions another reason for the rare occurrence of the disease in commercial plantings in presented.

\section{Discussion.}

The systematic position of the organism responsible for bacterial wilt of tomato, eggplant, pepper and potato in Puerto Rico has been repeatedly questioned, because although morphologically and physiologically similar to B. solanacearum E. F. S., it has been found unable to infect tobaceo under natural conditions or when artificially inoculated. In the Summer of 1931, the writer found a natural case cf wilt in tobacco exhibiting symptoms very similar to the so-called Granville Wilt in the United States. Cultural-studies of the organism involved identified it as similar to the ones isolated from other known suscept. Extensive direct and cross-inoculations with the exudate characteristic of the disease established its pathogenecity and intertransmission. Agar plates of this exudate yielded either pure cultures of an organism morphologically and physiologically identical with B. solanacearum E. F. S. or mixed colonies from which the organism was readily isolated. In the light of these results and of previous studies of Smith (l.c.) and Nolla (l.c.) when studying Puerto Rican material, it is concluded that $B$. solanacearum as occurs in Puerto Rico is identical to B. solanacearumu as described by Dr. Edwin F. Smith. 
The life history of the organism and suitable control measures were not included as a part of these studies because these phases of the problem have been adequately treated by other investigators here and elsewhere. The writer is of the opinion, however, that invasion of tobacco under our conditions very seldom, if ever, takes place through the aerial parts of the plant, but through the underground parts. In hundreds of wilted plants examined, the advance of the infection could always be traced from the roots towards the stem and never in the opposite direction. Aerial inoculations on peppers, however, have been successful.

Rotation of crops as a mean of control seems to have very limited, if any, possibilities. In fact, the first case of tobacco wilt was found in a field which has been growing sugar cane for many years. A field test of four varieties of tomatoes in a field not planted with any Solanaceous crop for at least 15 years, was a complete failure because more than 40 per cent of the plants were killed by the disease.

Breeding for resistance is, undoubtedly, the most promising control measure. Nolla (1.c.) found some varieties of eggplant and pepper highly resistant to the malady. Under our conditions the variety of potato Red Bliss Triumph is very susceptible while the Irish Cobbler, when grown under similar conditions, is very resistant. Tobacco varieties have shown a wide range of resistance. It is only in tomatoes that a resistant variety has not been found.

\section{ACKNOWLEDGMENT.}

The writer wishes to express his thanks to Dr. Melville T. Cook, Chief of the Division of Phytopathology, for his unfailing encouragement during the course of this investigation and for the revision of the manuscript.

\section{LITERATURE CITED.}

(1) Cook, Melville T.-A bacterial wilt of eggplants. Journal Dept. Agr. Puerto Rico 8 (4) : 14-16. 1 fig. 1924. Also in Phytopath, 15:55 (Abstract) 1925.

(2) Henricksen, H. C.-Vegetable Growing in Porto Rico. Porto Rico Agr. Exp. Sta. Bul. 7:1-58. 1906.

(3) Iorns, IV. J.-Report of the Horticulturist. Porto Rico Agr. Exp. Sta. Ann. Rpt. 1907:20-30. 1908.

(4) López Santiago, B.-Algunas enfermedades del tomate en Puerto Rico. Revista de Agricultura de Puerto Rico. 9: (6) 33-37, fig. 1-2. 1922.

(5) Nolla, J. A. B.-Studies on the Bacterial Wilt of the Solanaceae in Porto Rico. Journal of the Department of Agriculture of Porto Rico 15: (3) 287-308. 4 plates. 1931. 
(6) Seaver, Fred J. and Carlos F. Chardon.-Botany of Porto Rico and the Virgin Islands. Mycology. Sci. Surv. of Porto Rico and the Virgin Islands, New York Ac. Sc. 8: 1-208. 1926.

(7) Smith, E. F.-Bacteria in Relation to Plant Diseases. Carnegie Inst. of Washington, Publication 27, 3: 1-309, 1914.

(8) Stevenson, J. A. and R. C. Rose. Vegetable Diseases. Porto Rico Ins. Exp. Sta. Rept. 1916-17: 85, 87. 1917.

(9) Stevenson, J. A.-A check List of Porto Rican Fungi and a Host Index. Jour. Porto Rico Dept. Agri. 2: 125-264. 1918.

(10) Stanford, E. E. and Wolf, F. A.-Studies on Bacterium solanacearum. Phytopath. 7: (3) 155-165. 1 fig. 1917.

(11) Thomas, H. E.-Report of the Plant Pathologist. Porto Rico Agr. Exp. Sta. Ann. Rept. 1917:1-40. 1918.

\section{Explanation of Plates.}

Plate I.-Two nutrient agar plates using different dilutions from a broth culture made directly from tobaceo ooze. Only typical colonies of $B$. solanacearum developed. This ooze was used to inoculate plants shown on plate II.

PLATE II.-Upper: Plants of the "Ceniza" variety artificially inoculated with bacterial ooze from wilted tobaceo plants, photographed 10 days after the inoculation. Plants at left and right are showing typical symptoms. Middle plant, check.

Lower: Same as above using plants of "Utuado" variety.

I LATE III.-At left naturally wilted plant and at right healthy plant of the imported variety "Cash". 
PLATE I.

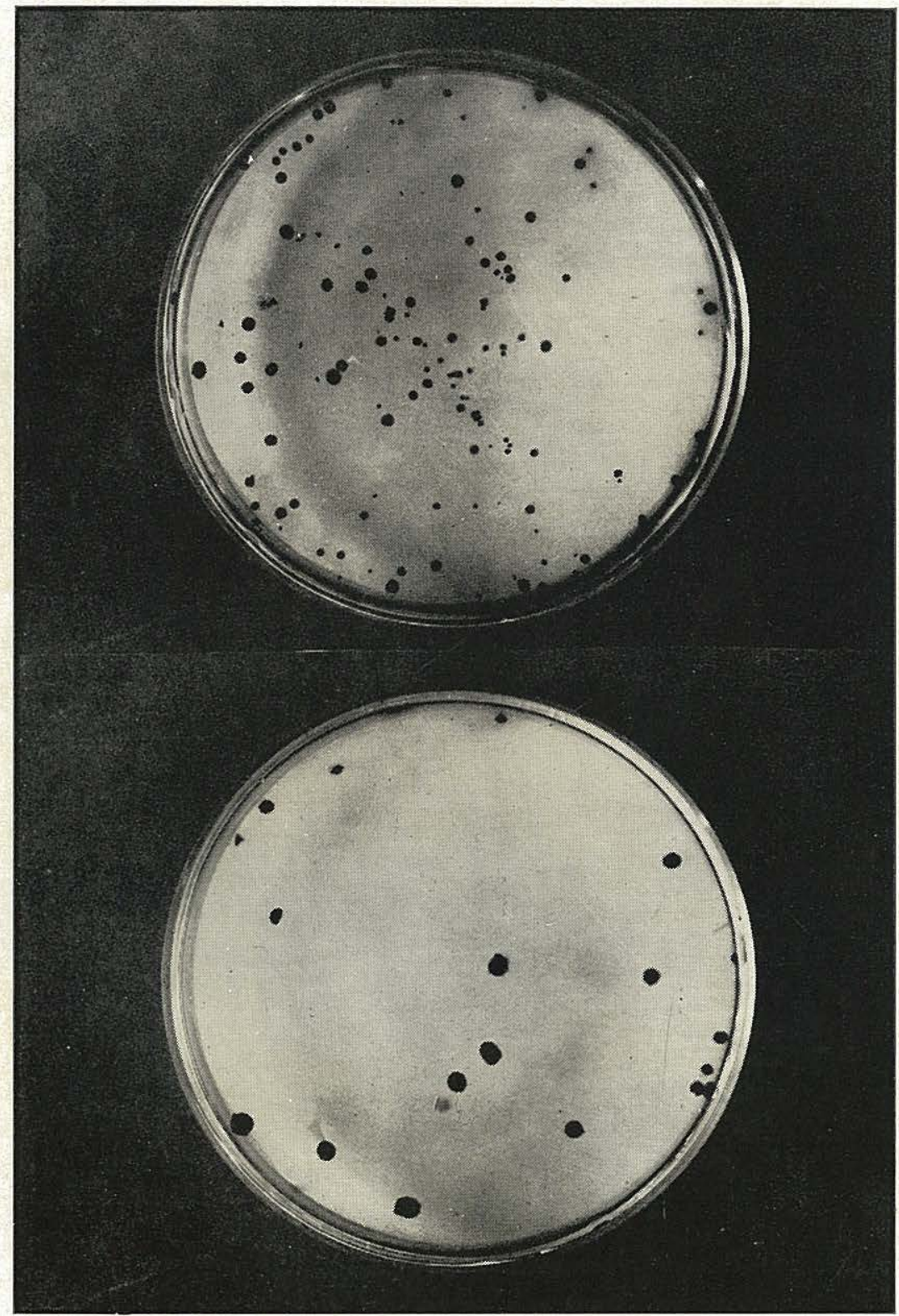


PLATE II.

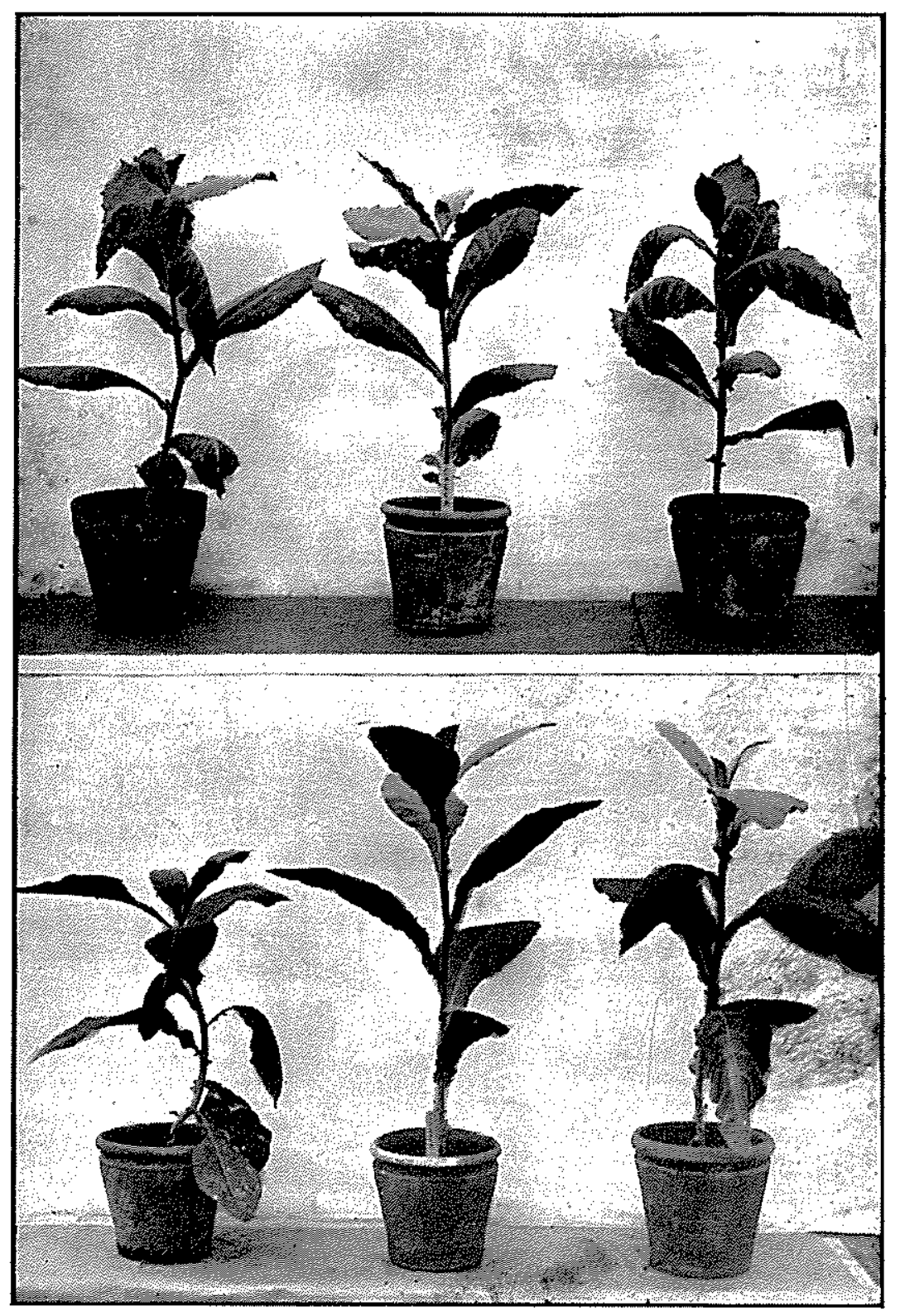




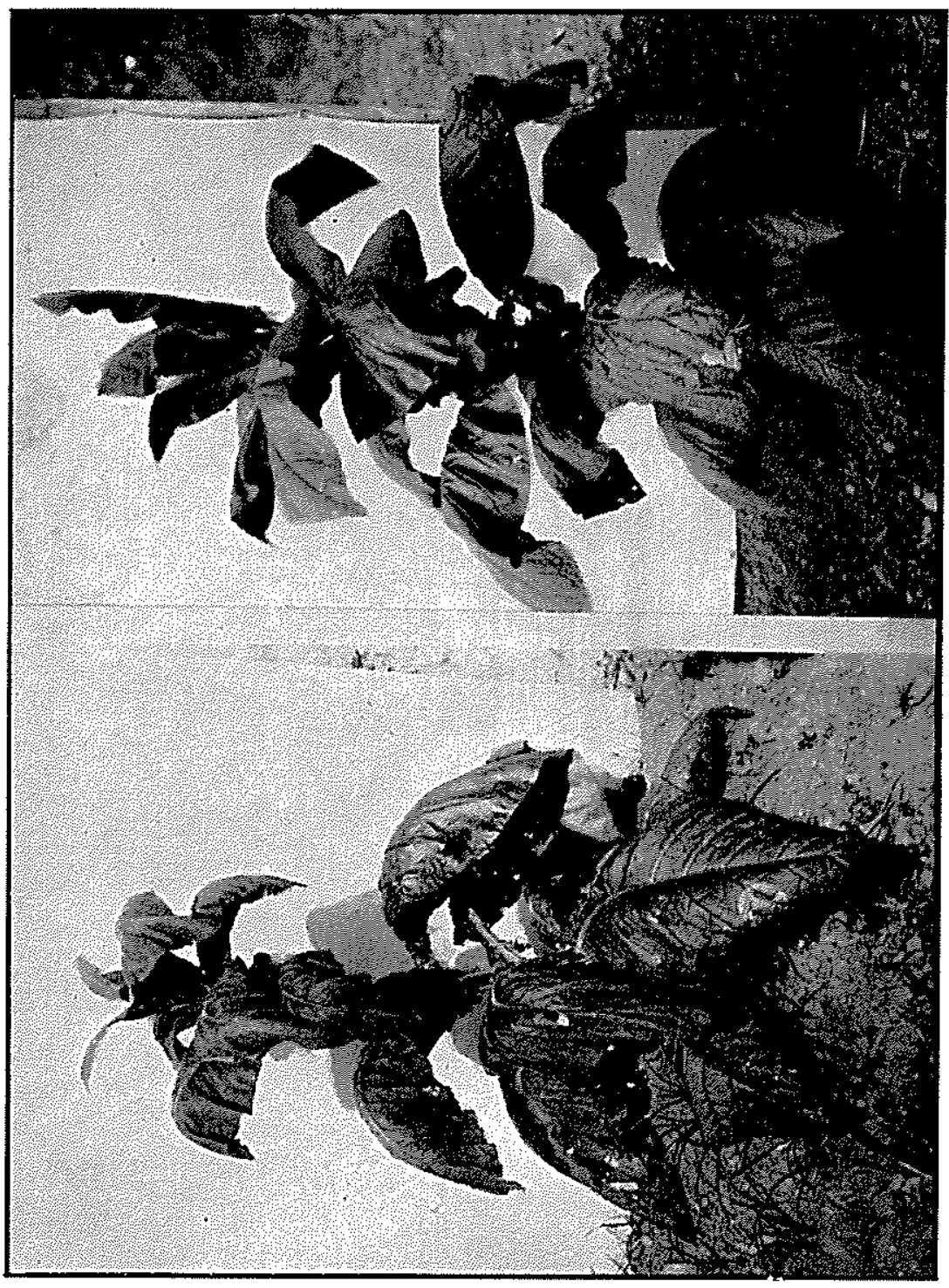

